\title{
A CONSTRUÇÃo de UM NOVO PARAdigma AMBIENTAL: A HERMENÊUTICA FILOSÓFICA DE HANS-GEORG GADAMER E A (IN) CONSTITUCIONALIDADE DA LEI
} $12.651 / 2012$

Cleide Calgaro ${ }^{1}$

Alessandra Antunes Erthal ${ }^{2}$

Resumo: No presente trabalho analisa-se a (in) constitucionalidade do Código Florestal - Lei 12.651/2012 e se propõem uma nova perspectiva a partir da hermenêutica gadameriana. O método utilizado é o hermenêutico. Conclui-se que a hermenêutica de Gadamer pode trazer uma nova compreensão as questões de direito ambiental, onde o intérprete pode vislumbrar a justiça ambiental e a mudança de paradigmas vigentes.

Palavras-chave: Meio ambiente; Hermenêutica Filosófica; Hans-Georg Gadamer; Direito Constitucional; Código Florestal.

\section{INTRODUÇÃO}

Pode-se considerar um marco para o Direito Ambiental Brasileiro o advento da Lei 12.651 de 2012, o Código Florestal. Logo após a promulgação do dispositivo, constituiu-se no Brasil acalorados debates sobre a efetivação da norma e sua eficiência.

Muito além de intervenções a direitos materiais, o dispositivo atingiu questões biológicas, socioeconômicas, éticas e conceituais. Dessa maneira, por maior que for o respaldo constitucional atribuído ao meio ambiente, observou-se que preceitos fundamentais poderiam ser relativizados e assim, o alerta se voltou para a forma que Brasil trata seu meio ambiente.

Logo, o Código Florestal tornou-se tema de Ações Diretas de Inconstitucionalidade, bem como de uma Ação Declaratória de Constitucionalidade. Para tanto o método utilizado para a presente pesquisa

\footnotetext{
${ }^{1}$ Doutora em Ciências Sociais na Universidade do Vale do Rio dos Sinos - UNISINOS. Pós-Doutora em Filosofia e em Direito ambos pela Pontifícia Universidade Católica do Rio Grande do Sul - PUCRS. Doutoranda em Filosofia pela Pontifícia Universidade Católica do Rio Grande do Sul - PUCRS, na condição de taxista CAPES. Doutoranda em Direito pela Universidade de Santa Cruz do Sul - UNISC. Professora da Graduação e Pós-Graduação em Direito na Universidade de Caxias do Sul. É Líder do Grupo de Pesquisa "Metamorfose Jurídica” da Universidade de Caxias do Sul-UCS e ViceLíder do Grupo de Pesquisa "Filosofia do Direito e Pensamento Político" da Universidade Federal da Paraíba-UFPB. Atua como pesquisadora no Grupo de pesquisa "Regulação ambiental da atividade econômica sustentável (REGA)" da Escola Superior Dom Helder Câmara. Orcid: https://orcid.org/0000-0002-1840-9598. CV: http://lattes.cnpq.br/8547639191475261.E-mail: ccalgaro1@hotmail.com

${ }^{2}$ Bacharel em Direito pela Universidade de Caxias do Sul. Ex-bolsista Fapergs. Ex-integrante do Grupo de pesquisa "Cultura Política, Políticas Públicas e Sociais". Universidade de Caxias do Sul - UCS, Rio Grande do Sul - brasil. E-mail: aaerthal@ucs.br
} 


\section{Quaestio Iuris}

vol. 12, nº .04, Riode Janeiro, 2019. pp. 590-607

DOI: $10.12957 /$ rqi.2020.39929

foi o hermenêutico, a partir do estudo de Gadamer e sua teoria como proposta de uma nova perspectiva de compreensão do direito ambiental na sociedade atual.

O presente trabalho busca analisar as Ações Direta de Inconstitucionalidade, e a partir de tal análise, ofertar uma nova perspectiva para o Direito ambiental, fundada na Hermenêutica Filosófica de Hans-Geog Gadamer.

Portanto, o estudo percorre duas áreas de conhecimento: o Direito e a Filosofia. Busca-se analisar o Código Florestal Brasileiro suas respectivas Ações de Inconstitucionalidade sob a ótica da Hermenêutica Filosófica de Hans-Georg Gadamer.

Ao tratar do Código Florestal, serão analisados o cenário e os processos políticos que culminaram com a alteração da Lei, bem como os contrapontos expostos nas Ações Diretas de Inconstitucionalidade propostas ao STF.

Serão identificadas as principais mudanças, e sob que fatores as alterações interferiram no meio ambiente. Busca-se identificar os conflitos existentes entre a nova legislação e a realidade ambiental brasileira. Assim, passa-se a analisar as ações diretas de inconstitucionalidade (ADIn), propostas em face da referida legislação, apontando as implicações da norma.

Conclui-se que se multiplicam a cada dia os problemas ambientais, e o direito como disciplina dinâmica, não pode manter uma postura estagnada, baseada em dogmáticas que já não responde mais aos clamores sociais. Assim, a hermenêutica filosófica está encarregada do papel de ajudar o direito, a se modificar e possibilitar o nascimento de novo saber ambiental.

\section{ANÁLISE DAS AÇÕES DE INCONSTITUCIONALIDADE SOBRE O NOVO CÓDIGO FLORESTAL (LEI 12.651 DE 2012)}

A Lei 12.651/2012, conhecida como o Novo Código Florestal, foi promulgada com o pretexto de modernizar a legislação que tratava das questões do uso e proteção das florestas em território nacional. Entretanto, o dispositivo instituiu grande debate acerca de sua constitucionalidade.

Seguidamente de sua publicação, o dispositivo tornou-se tema de Ações Diretas de Inconstitucionalidade. Com relação ao controle de Constitucionalidade, Moraes leciona:

Controlar a constitucionalidade significa verificar a adequação (compatibilidade) de uma lei ou de um ato normativo com a constituição, verificando seus requisitos formais e materiais. Dessa forma, no sistema constitucional brasileiro somente as normas constitucionais positivadas podem ser utilizadas como paradigma para a análise da constitucionalidade de leis ou atos normativos estatais (bloco de constitucionalidade). (MORAES, 2017, p. 741). 
Na Ação Direta de Inconstitucionalidade (ADI) o autor da ação judicial não alega a existência de lesão a direito próprio, mas atua como representante do interesse público, além disso, refere-se a questões que abrangem o direito de uma coletividade, e não de um direito individual. Ou seja, a proteção da Constituição em relação a outros dispositivos legais que possam ferir a sua essência e importância dentro do ordenamento jurídico. Especificamente no que trata do Código Florestal, é questionada uma disparidade entre os direitos garantidos e a realidade ambiental no Brasil.

Assim, rogou-se ao Judiciário a análise do tema, para que tais divergências existentes viessem a ser sanadas. Interessa mencionar o que ensina Antônio Herman Benjamin:

Embora o ofício do juiz não se limite à interpretação da lei, sem dúvida é esse mister complexo que mais consome energia e tempo no exercício da função jurisdicional. Verdade que, quanto mais madura e consolidada a disciplina jurídica, ou a legislação que lhe dá concretude e sustento, menos dificultosa fica a tarefa de dizer o Direito, exceção feita, como não poderia deixar de ser, as hipóteses novas, que continuam a aparecer em razão da natural evolução e transformação das relações humanos e da sua base ética, fática e tecnológica. (2014, p. 15-24).

Ainda, considerando se tratar de dispositivo recente, como o referido Código, Benjamin completa: "multiplicam-se as exigências técnicas ao juiz, mormente quando se vê chamado, para além da pura aplicação do novo texto a litígio particular, a arbitrar conflitos intertemporais e de valores éticos" (2014, p.15-24).

A realidade é que mesmo antes da lei produzir qualquer efeito, o Código Florestal foi modificado por diversos vetos presidenciais, posteriormente remendados pela Medida Provisória n. ${ }^{\circ}$ 571/2012, e por fim, convertido na Lei 12.727/2012.

No início 2013, poucos meses após a publicação do Código Florestal, foram ajuizadas três Ações Diretas de Inconstitucionalidade (ADI) pelo Ministério Público Federal (distribuídas sob os números 4.901, 4.902 e 4.903), e mais uma quarta, pelo Partido Socialismo e Liberdade - PSOL (sob o número 4.937). Como fundamento de todas as ADI's, encontra-se a violação a princípio da vedação do retrocesso em matéria de direitos fundamentais.

Além disso das quatro ADI's ajuizadas, foi ajuizada uma Ação Declaratória de Constitucionalidade (ADC), proposta pelo Partido Progressista (PP).

Convém mencionar que as referidas ações foram julgadas conjuntamente, tendo o julgamento se encerrado em 28 de fevereiro do ano de 2018. Ademais, serão objeto de estudo apenas as Ações Diretas de Inconstitucionalidade, tendo em vista que a abordagem é a análise da Inconstitucionalidade do Código Florestal.

Sobre o Código Florestal, o Ministro Antônio Herman Benjamin pontua: 
Poucas leis editadas a partir de 1988 carreiam tantas dificuldades e incertezas para o intérprete como o novo Código Florestal (Lei 12.651/12). Primeiro, porque não se propôs simplesmente a substituir, de maneira integral e absoluta, o regime legal anterior. Ao contrário, herda não só seus instrumentos mais característicos (p. ex., as Áreas de Preservação Permanente - APPs e a Reserva Legal), mas também a vasta jurisprudência que se formou sob o império da estrutura normativa a que sucede. (2014, p.164). (Grifo nosso)

Ainda, Benjamin reconhece que o novo Código Florestal sofre de problemas imensos de redação, assim, tornando abomináveis suas previsões. Benjamin completa:

[...] com sérias infrações, aqui e acolá, do próprio vernáculo, algo que só se explica se a contragosto aceitarmos que o legislador, no afã de agradar os vários setores econômicos contrários à lei de 1965, abdicou da marca da qualidade do trabalho objetivo de redação, indispensável mesmo na previsão de casuísmos e aberrações. (2014, p.164).

Além disso, constrói-se uma análise axiológica existente entre a norma e a realidade. No plano axiológico, o Ministro completa:

[...] no plano axiológico, o Código Florestal não conseguirá evitar os pilares que hoje demarcam o território do razoável (e, no juízo de razoabilidade, o razoável ecológico), pois navega em águas de renovada ética da vida e da responsabilidade planetária, que sem dúvida servirá para conter as suas piores absurdidades, aquelas que violam o conhecimento científico e a lógica da efetividade que deve orientar a função legislativa. (BENJAMIN, 2014, p.164).

Em seu voto proferido no julgamento do Código Florestal, o Ministro Celso de Mello alude a questão do plano axiológico:

A superação dos antagonismos existentes entre princípios e valores constitucionais há de resultar da utilização de critérios que permitam ao poder público ponderar e avaliar, em função de determinado contexto e sob uma perspectiva axiológica concreta, qual deva ser o direito a preponderar no caso, considerada a situação de conflito ocorrente, desde que, no entanto, a utilização do método da ponderação de bens e interesses não importe em esvaziamento do conteúdo essencial dos direitos fundamentais, entre os quais avulta, por sua significativa importância, o direito à preservação do meio ambiente. (CONJUR, 2019, sem paginação).

O Ministro ainda afirmou que, em casos de dúvida como por exemplo, se há dúvida com relação a determinada conduta irá prejudicar o meio ambiente e os cidadãos, deve prevalecer o princípio "in dubio pro natura" (CONJUR, 2019, sem paginação).

No entanto, o Novo Código Florestal com um viés técnico, representou retrocesso na tutela e status de proteção da ambiental no país. Além disso, realizou verdadeira mudança na forma de tutela constitucional da proteção, atribuindo valor pecuniário ao meio ambiente. 
Ao propor as ADI's no 4901, no 4902 e no 4903, a Procuradoria-Geral da República solicitou junto ao Superior Tribunal Federal a concessão de medida cautelar para a suspensão da eficácia de alguns dispositivos da Lei, observando o que está previsto no art. 10 da Lei $n^{\circ}$ 9.868/99.

Na ADI 4901, a primeira a ser proposta pela Procuradoria-Geral da União a ação propõe a impugnação dos seguintes dispositivos: art. $12, \S 4^{\circ}, \S 5^{\circ}, \S 6^{\circ}, \S 7$ e $\S 8$; art. $13^{\circ}, \S 1^{\circ}$; art. 15 ; art. $48, \S$ $2^{\circ}$; art. $66, \S 30, \S 5^{\circ}$, II, III e IV e $\S 6^{\circ}$ e 68 , todos da Lei $12.651 / 12$.

Além disso, solicita-se a interpretação conforme a constituição ao art. 28 da Lei 12.651/12, nos termos do pedido ao final formulado (BRASIL, STF, AÇÃO DIRETA DE INCONSTITUCIONALIDADE: ADI 4901, 2018)3.

Já na ADI 4902, os dispositivos remetidos são: $\S 3^{\circ}$ do art. 7; $\S 4^{\circ}$ e $\S 5^{\circ}$ do art. 59 e artigos 60 , 61-A, 61-B, 61-C, 63, 67 e 78-A todos da Lei 12.651/12. Reporta-se a trecho da inicial:

[..] todos os dispositivos legais impugnados, ao diminuírem o padrão de proteção ambiental e até mesmo extinguirem espaços territoriais especialmente protegidos, ofendem mandamentos constitucionais explícitos, justificando-se, por esse motivo, a abertura da via do controle abstrato de constitucionalidade. (BRASL, STF, AÇÃO DIRETA DE INCONSTITUCIONALIDADE: ADI 4902, 2018). ${ }^{4}$

Posteriormente, foi ajuizada a ADI $4903^{5}$, que refere-se a inconstitucionalidade dos seguintes dispositivos: art. $3^{\circ}$, VIII, alínea "b", IX, XVII, XIX e parágrafo único; art. $4^{\circ}$, III, IV, $\S 1^{\circ}, \S 4^{\circ}, \S 5^{\circ}, \S$ $6^{\circ}$; art. $5^{\circ}$; art. $8^{\circ}, \S 2$; art. 11 e art. 62 , todos da Lei 12.651/12.

Também menciona-se a ADI $4937^{6}$, proposta pelo Partido Socialismo e Liberdade (PSOL) no Supremo Tribunal Federal (STF), contra dispositivos do novo código florestal.

Para o PSOL, os dispositivos questionados fragilizam a proteção do meio ambiente, mitigam os seus princípios e frustram a intenção do constituinte originário. In verbis:

\footnotetext{
3 Consultar: BRASIL. STF. AÇÃO DIRETA DE INCONSTITUCIONALIDADE: ADI 4901. Relator: Ministro Luiz Fux. DJ: 28/02/2018. STF, 2018. http://redir.stf.jus.br/estfvisualizadorpub/jsp/consultarprocessoeletronico/ConsultarProcessoEletronico.jsf?seqobjetoinci dente $=4355097$. Acesso em: 18 de junho de 2018 .

4 Consultar: BRASIL. STF. AÇÃO DIRETA DE INCONSTITUCIONALIDADE: ADI 4902. Relator: Ministro Luiz Fux. DJ: 28/02/2018. STF, 2018. Disponível em: http://redir.stf.jus.br/estfvisualizadorpub/jsp/consultarprocessoeletronico/ConsultarProcessoEletronico.jsf?seqobjetoinci dente $=4355128$. Acesso em: 18 de junho de 2018 .

5 Consultar: BRASIL. STF. AÇÃO DIRETA DE INCONSTITUCIONALIDADE: ADI 4903. Relator: Ministro Luiz Fux. DJ: 28/02/2018. STF, 2018. http://redir.stf.jus.br/estfvisualizadorpub/jsp/consultarprocessoeletronico/ConsultarProcessoEletronico.jsf?seqobjetoinci dente $=4355144$. Acesso em: 18 de junho de 2018 .

6 Consultar: BRASIL. STF. AÇÃO DIRETA DE INCONSTITUCIONALIDADE: ADI 4937. Relator: Ministro Luiz Fux. DJ: 28/02/2018. STF, $2018 . \quad$ Disponível em: http://redir.stf.jus.br/estfvisualizadorpub/jsp/consultarprocessoeletronico/ConsultarProcessoEletronico.jsf?seqobjetoinci dente $=4388129$. Acesso em: 18 de junho de 2018 .
} 
A Lei $\mathrm{n}^{\circ}$ 12.651, de 2012, alterada pela Lei $\mathrm{n}^{\circ}$ 12.727, de 2012, padece de inconstitucionalidade no que tange aos seguintes dispositivos: art. $3^{\circ}$, VIII, "b", art. $7^{\circ}$, $\S 3^{\circ}$; art. $13^{\circ}, \S 1^{\circ}$; art. 44 ; art. $48, \S 2^{\circ}$; art. $59 \S 2^{\circ}, \S 4^{\circ}$ e $\S 5^{\circ}, 60,61-A, 61-B, 61-\mathrm{C}, 63$, todos da Lei 12.651/12. 2.2 Pontualmente, conforme será demonstrado, todos os dispositivos supra elencados fragilizam a proteção do meio ambiente, mitigam os seus princípios e frustram a intenção do constituinte originário, que fez consignar expressamente no art. 225 da Lei Fundamental. (BRASIL, STF, AÇÃO DIRETA DE INCONSTITUCIONALIDADE: ADI 4937, 2018).

Nota-se que, a razão tantas propostas de ações diretas de Inconstitucionalidades, se dá ao fato de que o referido dispositivo sofreu diversas alterações já em seu primeiro ano de vigência, e somente com o decurso do tempo, foi se verificando as situações de instabilidade jurídica.

Cumpre destacar ainda, as ADI's ajuizada acometem-se a dispositivos diferentes do Código Florestal. Dos 84 artigos do referido dispositivo, 58 foram questionados pelas ADI's, somente quatro pontos foram modificados pelo Supremo Tribunal Federal.

Logicamente, torna-se inviável ao presente trabalho analisar cada ponto discutido nas ações de Inconstitucionalidade do Código Florestal. Assim, nossa análise ficará adstrita apenas aos dispositivos de mudanças mais expressivas.

Observa-se que as referidas ações têm como fundamento o art. $186 \mathrm{CF} / 88$, que versa sobre a função social da propriedade, bem como o art. $225 \mathrm{CF} / 88$, que leciona acerca do direito ao meio ambiente ecologicamente equilibrado, pois são os dispositivos mais afetados pela nova norma. Dessa forma,

a Constituição Federal, em seu art. 225, determina que todos têm direito ao meio ambiente ecologicamente equilibrado, bem de uso comum do povo e essencial à sadia qualidade de vida, impondo-se ao Poder Público e à coletividade o dever de defendê-lo e preservá-lo para as presentes e futuras gerações. Dela derivam as demais leis, resoluções, normas e condutas que regem, hoje, a legislação ambiental brasileira, que, em todos os seus aspectos, busca o desenvolvimento sustentável. (CADERNOS da EJEF, 2016, p.65).

Um dos pontos cruciais debatidos nas ADI's, refere-se a Reserva Legal. Assim, é necessário expor o que vem a ser a reserva florestal legal, conforme Granziera ensina:

interior de uma propriedade ou posse rural, delimitada nos termos do art. 12, com a função de assegurar o uso econômico de modo sustentável dos recursos naturais do imóvel rural, auxiliar a conservação e a reabilitação dos processos ecológicos e promover a conservação da biodiversidade, bem como o abrigo e a proteção de fauna silvestre e da flora nativa. (GRANZIERA, 2015, p.496).

Na ADI 4901, verifica-se importância do instituto da Reserva Legal, ao apresentar: é inegável que a Constituição Federal recepcionou a instituição das áreas de reserva legal como forma de garantir a 
execução dos objetivos constitucionais de proteção do meio ambiente. (BRASIL. STF. AÇÃO DIRETA DE INCONSTITUCIONALIDADE: ADI 4901, 2018).

O texto em vigor do Código Florestal, afirma empregar o princípio do desenvolvimento sustentável, entretanto, no decorrer dos dispositivos que regem o instituto da Reserva Legal, a norma flexibilizou as regras para sua utilização.

Classificam-se quatro tipos de reserva florestal legal: na Amazônia Legal em que o percentual mínimo em relação à área do imóvel para a reserva legal é de $80 \%$ quando situado em áreas de florestas; na área de cerrados que já é 35\%; na área de campos gerais é de $20 \%$ e nas outras áreas do País também é de $20 \%$. Sendo que de acordo com o art. $3^{\circ}$, I, do Código Florestal corresponde a Amazônia Legal os Estados do Acre, Pará, Amazonas, Roraima, Rondônia, Amapá e Mato Grosso e as regiões situadas ao norte do paralelo $13^{\circ} \mathrm{S}$, dos Estados de Tocantins e Goiás, e ao oeste do meridiano de $44^{\circ} \mathrm{W}$, do Estado do Maranhão. (BRASIL, Lei 12.651/12, 2018).

O art. 12 da Lei $12.651 / 12$ em seus $\S \S 4^{\circ}$ e $5^{\circ}$, prevê uma possibilidade de diminuição da área de reserva legal, in verbis:

Art. 12. Todo imóvel rural deve manter área com cobertura de vegetação nativa, a título de Reserva Legal, sem prejuízo da aplicação das normas sobre as Áreas de Preservação Permanente, observados os seguintes percentuais mínimos em relação à área do imóvel, excetuados os casos previstos no art. 68 desta Lei:

I - localizado na Amazônia Legal:

a) $80 \%$ (oitenta por cento), no imóvel situado em área de florestas;

b) 35\% (trinta e cinco por cento), no imóvel situado em área de cerrado;

c) $20 \%$ (vinte por cento), no imóvel situado em área de campos gerais;

II - localizado nas demais regiões do País: $20 \%$ (vinte por cento).

§ 4o Nos casos da alínea $a$ do inciso I, o poder público poderá reduzir a Reserva Legal para até $\mathbf{5 0 \%}$ (cinquenta por cento), para fins de recomposição, quando o Município tiver mais de $50 \%$ (cinquenta por cento) da área ocupada por unidades de conservação da natureza de domínio público e por terras indígenas homologadas.

§ 5 o Nos casos da alínea $a$ do inciso I, o poder público estadual, ouvido o Conselho Estadual de Meio Ambiente, poderá reduzir a Reserva Legal para até $50 \%$ (cinquenta por cento), quando o Estado tiver Zoneamento Ecológico-Econômico aprovado e mais de $65 \%$ (sessenta e cinco por cento) do seu território ocupado por unidades de conservação da natureza de domínio público, devidamente regularizadas, e por terras indígenas homologadas. (Grifo nosso). (BRASIL, Lei $12.651 / 12,2018)$.

A redução das áreas de reserva legal constitui retrocesso ambiental, dessa maneira, afirma-se na ADI 4901: “as finalidades ecológicas das unidades de conservação e das áreas de reserva legal são substancialmente distintas, de forma que tais instrumentos de proteção ambiental não podem ser equiparados" (BRASIL. STF. AÇÃO DIRETA DE INCONSTITUCIONALIDADE: ADI 4901, 2018).

O segundo ponto de destaque das ações, relaciona-se a intervenção em áreas de preservação permanente na hipótese de utilidade pública e interesse social: 
Conforme salienta o Ministro do Superior Tribunal de Justiça, Antônio Herman Benjamin, a Área de Preservação Permanente (APP) "como sua própria denominação demonstra - é área de "preservação" e não de "conservação"-, não permite exploração econômica direta (modere ira. agricultura ou pecuária), mesmo que com manejo ", tudo com objetivo de favorecer sua função ambiental, qual seja, a preservação dos recursos hídricos, da paisagem, da estabilidade geológica, da biodiversidade e a proteção do solo. (BRASIL. STF. AÇÃO DIRETA DE INCONSTITUCIONALIDADE: ADI 4903, 2018).

O conceito legal de Área de Preservação Permanente (APP) é dado pelo Código Florestal, em seu art. $3^{\circ}$, II:

II - Área de Preservação Permanente - APP: área protegida, coberta ou não por vegetação nativa, com a função ambiental de preservar os recursos hídricos, a paisagem, a estabilidade geológica e a biodiversidade, facilitar o fluxo gênico de fauna e flora, proteger o solo e assegurar o bem-estar das populações humanas. (BRASIL. LEI N ${ }^{\mathrm{o}}$ $12.651 / 2012,2018)$.

Aparentemente, ao estabelecer uma função ambiental para as Áreas de Preservação Permanente, a lei admite a relevância desses espaços para proteção. Entretanto, alguns usos e intervenções em áreas de preservação permanente foram excepcionalmente admitidos pelo Código Florestal, em casos de utilidade pública, interesse social ou de intervenções de baixo impacto ambiental.

Tal dispositivo fere o que preleciona o art. 225 da Constituição Federal de 1988, na medida em que: “algumas das hipóteses de utilização das áreas de preservação permanente previstas na Lei comprometem os atributos que justificam sua proteção, violando, por consequência, o art. $225, \S 1^{\circ}$, da Constituição Federal”. (BRASIL. STF. AÇÃO DIRETA DE INCONSTITUCIONALIDADE: ADI 4903, 2018).

Assim, pode-se afirmar que houve uma relativização dos direitos a proteção ambiental. Destacase a análise de Granziera, ao expor: "Daí a importância de se entender o reflexo da função ambiental na manutenção do equilíbrio entre os vários recursos naturais e que não pode ser objeto de relativização". (GRANZIERA, 2015. p. 466).

Outro ponto lastimável na legislação, arguido nas ações, é o estabelecimento de imunidade à físcalização e anistia de multas (art. 59, $\S \S 4^{\circ}$ e $5^{\circ}$ ). Lei 12.651, estabelece:

Art. 59. A União, os Estados e o Distrito Federal deverão, no prazo de 1 (um) ano, contado a partir da data da publicação desta Lei, prorrogável por uma única vez, por igual período, por ato do Chefe do Poder Executivo, implantar Programas de Regularização Ambiental - PRAs de posses e propriedades rurais, com o objetivo de adequá-las aos termos deste Capítulo.

4o No período entre a publicação desta Lei e a implantação do PRA em cada Estado e no Distrito Federal, bem como após a adesão do interessado ao PRA e enquanto 
estiver sendo cumprido o termo de compromisso, o proprietário ou possuidor não poderá ser autuado por infrações cometidas antes de 22 de julho de 2008 , relativas à supressão irregular de vegetação em Áreas de Preservação Permanente, de Reserva Legal e de uso restrito.

§ $5 \underline{0}$ A partir da assinatura do termo de compromisso, serão suspensas as sanções decorrentes das infrações mencionadas no $\S 4 \underline{0}$ deste artigo e, cumpridas as obrigações estabelecidas no PRA ou no termo de compromisso para a regularização ambiental das exigências desta Lei, nos prazos e condições neles estabelecidos, as multas referidas neste artigo serão consideradas como convertidas em serviços de preservação, melhoria e recuperação da qualidade do meio ambiente, regularizando o uso de áreas rurais consolidadas conforme definido no PRA. (Grifo nosso). (BRASIL. LEI No 12.651/2012, 2018).

Aqui nota-se que não é compatível a disposição do texto legal com o dever constitucional de preservar e restaurar os processos ecológicos, ademais: "de forma deliberadamente contrária aos mandamentos constitucionais inscritos nos artigos $225, \S 1^{\circ}$, I e $\S 3^{\circ}$, da Constituição da República, tais dispositivos legais inserem uma absurda suspensão das atividades fiscalizatórias do Estado". (BRASIL. STF. AÇÃO DIRETA DE INCONSTITUCIONALIDADE: ADI 4902, 2018).

Nessa sequência, a ADI 4902 refere-se ao o art. 60 do Código Florestal, que prevê a suspensão da punibilidade e a extinção da punibilidade dos crimes previstos nos artigos 38, 39 e 48 da Lei 9,605/98, nos seguintes termos:

Art. 60. A assinatura de termo de compromisso para regularização de imóvel ou posse rural perante o órgão ambiental competente, mencionado no art. 59, suspenderá a punibilidade dos crimes previstos nos arts. 38, 39 e 48 da Lei 9.605, de 12 de Fevereiro de 1998, enquanto o termo estiver sendo cumprido.

$\S 1$ o A prescrição ficará interrompida durante o período de suspensão da pretensão punitiva.

$\S 2 \underline{0}$ Extingue-se a punibilidade com a efetiva regularização prevista nesta Lei. (BRASIL. STF. AÇÃO DIRETA DE INCONSTITUCIONALIDADE: ADI 4902, 2018).

Menciona-se que os artigos 38 e 39 da Lei 9.605/98 dizem respeito a delitos ambientais como causar dano a áreas de preservação permanente e praticar o corte raso de vegetação. Dessa maneira é notável a indignação da Procuradoria Geral da República ao expor: "os dispositivos normativos impugnados, além de tornarem caótico o sistema de controle ambiental no Brasil, afrontam de forma severa o art. 225, $\S 3^{\circ}$, da Constituição Federal". (BRASIL. STF. AÇÃO DIRETA DE INCONSTITUCIONALIDADE: ADI 4902, 2018).

Lamentavelmente, um dos dispositivos mantidos pelos Ministros do STF foi justamente a anistia a produtores rurais que desmataram áreas protegidas antes de 2008. Para o Ministro Celso de Mello, o perdão "não se reveste de conteúdo arbitrário nem compromete a tutela constitucional em tema de meio ambiente". (BRASIL. STF. AÇÃO DIRETA DE INCONSTITUCIONALIDADE: ADI 4902, 2018). 
Segundo o ministro, a anistia é a expressão da "clemência do Estado" e se estende a crimes comuns, e não apenas a delitos políticos.

Oportuno é o momento para trazer o princípio da Vedação ao Retrocesso Ambiental, consagrado pelo Direito Ambiental Constitucional, segundo Granziera:

O princípio da proibição do retrocesso em matéria ambiental refere-se à ma- nutenção das normas protetoras do meio ambiente, conforme estabelecido nos arts. 225 e 170 da Constituição Federal. O retrocesso refere-se a uma norma que pode pôr em risco a proteção de um direito fundamental, que no caso do meio ambiente, vem sendo consolidado ao longo do tempo.59 Assim, esse princípio fundamenta-se na premissa de que as alterações das normas infraconstitucionais não podem ofender o equilíbrio do meio ambiente, dimensão objetiva do direito protegido, e que não pode ser relativizado. (GRANZIERA, 2015. p. 74).

De acordo com o princípio supramencionado, o Estado não deve tomar medidas, tanto legislativas ou administrativas, para restringir o âmbito de efetividade dos direitos socioambientais.

Isto posto, é possível afirmar a inconstitucionalidade de muitos desses dispositivos, exatamente em razão de supostamente operar um retrocesso em matéria ambiental.

Por fim, os Ministros do Supremo Tribunal Federal declararam a maioria dos dispositivos constitucionais, como fundamento o princípio da separação de poderes e o entendimento de que a vedação do retrocesso ambiental não impede a edição de leis sobre o assunto (BRASIL. STF. AÇÃO DIRETA DE INCONSTITUCIONALIDADE: ADI 4903, 2018), nos termos do voto do ministro Celso.

Apenas dois os pontos julgados inconstitucionais, são eles: Art. $3^{\circ}$, inciso VIII, alínea $b$ - foram julgadas inconstitucionais as expressões "gestão de resíduos" e "instalações necessárias à realização de competições esportivas estaduais, nacionais ou internacionais", nos mesmo termos do voto do relator; e Art. $3^{\circ}$, parágrafo único - declarado inconstitucional nas expressões "demarcadas e tituladas", também nos termos do voto do relator. (BRASIL. STF. AÇÃO DIRETA DE INCONSTITUCIONALIDADE: ADI 4903, 2018).

Ademais, os ministros decidiram por dar interpretação conforme a $\mathrm{CF} / 88$ dos seguintes dispositivos: Art. $3^{\circ}$, incisos VIII e IX - Interpretação conforme a CF/88 para condicionar a intervenção excepcional em APP por interesse social ou utilidade pública à inexistência de alternativa técnica ou locacional à atividade proposta; Art. $3^{\circ}$, inciso XVII - Interpretação conforme a CF/88 para fixar a interpretação no sentido de que os entornos de nascentes e olhos d'água intermitentes configuram área de preservação permanente. Art. $4^{\circ}$, Inciso IV - Interpretação conforme também para fixar o entendimento de que os entornos das nascentes e dos olhos d'água intermitentes são áreas de preservação ambiental. Art. $48, \S 2^{\circ}$ - Interpretação conforme a $\mathrm{CF} / 88$ para que a compensação seja apenas entre áreas com mesma identidade ecológica. Art. 59, $\S 4^{\circ}$ - Interpretação conforme a $\mathrm{CF} / 88$. Art. $59 \S 5^{\circ}$ - Interpretação 
conforme a CF/88. (BRASIL. STF. AÇÃO DIRETA DE INCONSTITUCIONALIDADE: ADI 4903, 2018).

Os votos da maior parte dos ministros reafirmam fundamentos importantes do direito coletivo ao meio ambiente, entretanto, não foi suficiente para convencer os Ministros da inconstitucionalidade da norma.

\section{A FUSÃO DE HORIZONTES: A CONSTRUÇÃO DE UM SABER AMBIENTAL}

Nas questões ambientais, a dogmática jurídica já não consegue suprir com respostas adequadas, a desordem entre direitos garantidos e a realidade. Assim, é necessário o surgimento de um novo paradigma. Com relação aos paradigmas, Navarro apresenta a afirmação de Kuhn:

[...]conjunto de ilustrações recorrentes e quase padronizadas de diferentes teorias nas suas aplicações conceituais, instrumental e na observação. Essas são os paradigmas da comunidade, revelados nos seus manuais, conferências e exercícios de laboratórios. (KUHN apud NAVARRO, 2014, p. 181).

Os paradigmas seriam algo mutável, que adotados no decorrer da história, oferecem problemas e soluções. Em determinado período, o paradigma precisa entrar em crise para surgir novos métodos e problemas, uma revolução. As revoluções científicas acontecem a partir de um desconforto que a ciência dominante causa, gerando um período de insegurança. (NAVARRO, 2015, p.192). Essa revolução também só é possível pois em determinado período de crise, as regras relaxam, abrindo espaço para pesquisas novas.

Na visão de Navarro, a hermenêutica filosófica:

(...) ao contrário das teorias interpretativas antecessoras, não está preocupada com a elaboração de um método interpretativo que fundamente a compreensão. Sua preocupação vai além dos métodos, propondo-se a demonstrar algo que é anterior à utilização dos métodos, precedendo a ciência moderna. Assim, não se trata de elaborar uma teoria geral da interpretação, mas sim encontrar o ponto em comum de todas as formas de compreensão, mostrando que não se trata de um mero comportamento subjetivo frente a um objeto, mas sim frente a uma historicidade da qual o próprio intérprete faz parte (2014, p.145).

Nesse sentido, Bleicher elucida que: "A filosofia de Gadamer completa a teoria ontológicaexistencial da compreensão e, simultaneamente, constitui a base da sua superação, através da tônica na linguisticidade da compreensão". (2002, p.153). 


\title{
Quaestio Iuris
}

vol. 12, nº .04, Riode Janeiro, 2019. pp. 590-607

DOI: $10.12957 /$ rqi.2020.39929

Diante dessa análise, para o direito ambiental se tornar efetivo, propõe-se uma revolução de paradigma. Conforme confirma-se pelo julgamento do Código Florestal, a carência da efetividade do direito ambiental resta demostrada pela incompreensão judicial do direito ambiental. Para Navarro:

É possível, destarte, reconhecer que a crise do direito ambiental possui hoje duas frentes: a redução dos níveis legais de proteção por meio de novas legislações retrocessivas e ainda a negação da aplicação dos dispositivos legais existentes em face de uma alegada "flexibilidade" do direito ambiental frente a proteção econômica e social. (2014, p.182).

A hermenêutica filosófica de Hans-Georg Gadamer oferece a superação desses paradigmas ambientais e a construção para um novo. A hermenêutica não se restringe apenas métodos, mas sim a compreensão do direito e do papel exercido pelo intérprete. Gadamer, em sua obra Verdade e Método II, preleciona que:

\begin{abstract}
A história da compreensão não é menos antiga e honorável. [...]. Poderíamos apelar para o fato de que o novo movimento de educação sofística impulsionou de fato a interpretação de frases poéticas famosas, adotando-as artificialmente como exemplos pedagógicos. (2011, p. 274).
\end{abstract}

$\mathrm{Na}$ hermenêutica filosófica de Gadamer evidencia-se a importância do pré-conceitos no momento da compreensão. Aquele que compreende realiza um projetar, já coloca sua opinião prévia.

Para compreender o direito ambiental, torna-se fundamental identificar alguns aspectos da précompreensão, seja quanto a interpretação, quando ao conteúdo. Especificamente no direito, os juristas estão atrelados a hábitos linguísticos e comportamentos reiterados.

Dessa forma, hermenêutica filosófica Gadameriana propõe o reconhecimento desse senso comum e desmitificar a pré-compreensão do intérprete. Conforme completa Navarro: "não basta a interpretação dos textos: é fundamental a interpretação da própria interpretação. Em outras palavras, não basta interpretar a lei, é fundamental que se esclareça o modo como essa interpretação ocorre". (2014, p.185). Deve-se destacar que o intérprete é um ator social incluído dentro de uma historicidade.

$\mathrm{Na}$ questão da pré-compreensão do conteúdo em si do direito ambiental, deixa espaço para o intérprete dizer a respeito a ela. No julgamento do Código Florestal, é oportuno apresentar que ao tratar do art. 59, $\S 4^{\circ}$, os Ministros decidiram por dar interpretação conforme a Constituição Federal, entretanto, a norma deixou o sentido em aberto e cabe o intérprete conceituar e aplicar.

Conforme Navarro, se o intérprete tem uma visão mais conservadora de sustentabilidade, pode ser possível que para este a realização de atividades econômicas poluidoras sejam possíveis face à ponderação de outros interesses. (2015, p.195).

O saber ambiental não se limita ao aprendizado apenas das ciências ambientais, mas pressupõe que traga a questão do ser no tempo, na história, um reconhecimento das disparidades. 


\title{
Quaestio Iuris
}

vol. 12, nº .04, Riode Janeiro, 2019. pp. 590-607

DOI: $10.12957 /$ rqi.2020.39929

Navarro preconiza: "a proposta de um saber ambiental fundado na complexidade promove uma abertura a tudo aquilo que foi excluído pela racionalidade". (2014, p.187).

Mesmo que as questões ambientais concebam debates como o Novo Florestal, o direito ainda lida com os problemas ambientais de uma forma instrumental. Disso nasce a necessidade de um saber jurídico ambiental orientado pela pluralidade de possibilidades.

A chave para uma nova perspectiva do direito ambiental é a compreensão da existência de uma crise ecológica. Não basta o modelo cienticista para oferecer respostas adequadas ao direito ambiental ou a sua crise, é necessário a comunicação entre as diversas instâncias como a ética, a política, a ciência e a filosofia para nascer soluções práticas. (NAVARRO, 2015, p.200).

Com relação a linguagem e o direito ambiental, Navarro comenta:

\begin{abstract}
A hermenêutica filosófica propõe uma superação na visão segundo a qual a linguagem é uma terceira coisa que se interpõe entre o sujeito e objeto, pois passa-se a entender a linguagem como elemento universal constitutivo tanto do sujeito como do próprio objeto. (2014, p. 190).
\end{abstract}

Dessa forma se caracteriza a viragem linguística, onde deixa-se de compreender o mundo por meio da linguagem e passa-se a compreender a própria linguagem.

Para Gadamer, a existência do homem no mundo está constituída linguisticamente, de
forma que é a linguagem que introduz o homem em uma determinada relação e um
determinado comportamento com relação ao mundo. Assim, o mundo somente é mundo
na medida em que vem à linguagem, ao mesmo tempo que a linguagem só tem sua
verdadeira existência no fato de que nela se representa o mundo. (NAVARRO, 2014,
p.191).

A linguagem possui pluralidade de sentidos. A compreensão das leis ambientais ocorre através da compreensão de linguagem ambiental, cuja característica é a busca do sentido apenas no caso concreto. Para Navarro: "Não existe um único sentido das leis ambientais a ser apreendido, mas esse sentido será construído com a base na pré-compreensão do intérprete”. (2014, p.191).

A abertura que o Direito ambiental propõe, no sentido de que sempre há fendas, seja pela valoração de elementos, pela utilização de termos ou pela falta de referências, é um espaço para o desenvolvimento da hermenêutica filosófica Gadameriana. A linguagem não possui um sentido intrínseco a ela, mas um sentido socialmente constituído. O sentido é construído na interpretação.

Com conceito fundamental para hermenêutica filosófica, tem-se a noção de horizonte. Se realizarmos um exercício de se transferir para o horizonte do outro, e compreender sua posição, é possível também compreender suas opiniões.

Para Gadamer: 
Compreender é sempre o processo de fusão de horizontes [presente e passado] presumivelmente essa tensão em uma assimilação ingênua, mas em desenvolvê-la conscientemente. Esta é a razão por que o comportamento hermenêutico está obrigado a projetar um horizonte que se distinga do presente. (2011, p.474).

Para análise dos horizontes, é crucial o estudo do momento em que as leis foram promulgadas, ou seja, no Código Florestal o movimento político e econômico do país deveria ter sido considerado, pois o jurista deve ter conhecimento de todas as circunstâncias e contextos do momento em que se encontra.

O intérprete não deve apenas submeter-se a vontade do legislador, o passado é apenas um dos elementos da fusão de horizontes. Além disso, as tomadas de decisões precisam afastar-se da lógica econômica predominante, deixando de lado seu caráter imediatista.

Navarro destaca que para uma devida aplicação do direito ambiental, é de grande valia a sua análise por meio dos elementos centrais da hermenêutica filosófica: a universalidade da linguagem, a précompreensão e a fusão de horizontes. (2015, p. 220).

$\mathrm{Na}$ visão da Hermenêutica Filosófica, as práticas jurídicas devem levar em consideração o âmbito da aplicação da norma, bem como as consequências jurídicas.

Navarro completa:

Por meio do diálogo entre o direito e tudo aquilo que foi excluído do âmbito jurídico, é possível sustentar um novo saber jurídico ambiental aberto à complexidade da realidade e à sua multidimensionalidade ancorado no paradigma constitucional e comprometido com a modificação radical das circunstâncias fáticas de exclusão socioambiental e degradação ambiental reiterada. (2014, p.213).

Bem além da preocupação com a mera reprodução do sentido das normas de Direito ambiental, ambiciona-se uma nova visão interpretativa, a abertura do direito ao diálogo e a assimilação das disparidades, para nascer uma verdadeira proteção ambiental.

\section{CONSIDERAÇÕES FINAIS}

Os elementos do Novo Código Florestal apresentados no presente estudo são apenas alguns exemplos do retrocesso ocasionado em matéria ambiental. A nova Lei, como visto, flexibilizou institutos importantíssimos e é evidente que, diminui-se, a esfera de proteção do meio ambiente no ordenamento jurídico brasileiro. 
Com a Novo texto legal, houve a confirmação da inércia das autoridades, da predominância e força política de certos setores, bem como de uma "esquizofrenia" legislativa que, foi criando dispositivos legais absurdos e sem qualquer preocupação com a realidade ambiental Brasileira.

Dessa forma, foi atribuído ao Poder Judiciário a tarefa de sanar os embaraços causados pelo novo regramento. Entretanto, observou-se interpretações incoerentes e que geraram mais insegurança jurídica.

Por meio da decisão das Ações Diretas de Inconstitucionalidade estudadas, verificou-se a persistência do Judiciário Brasileiro a prender-se a dogmas que não respondem as necessidades sociais.

O interessante é que como argumento, a nova Legislação ambiental assentou-se no ordenamento jurídico, com justificativas de proteção a princípios Constitucionais.

Merece esclarecimento de que o papel do Judiciário não é prestar a simples tutela, a sociedade recorreu ao órgão para salvaguardar o meio ambiente, e o que se obteve de resposta foi uma total distorção de valores e desconsideração fatores históricos.

O intérprete é um ator social incluído dentro de uma historicidade, não basta uma simples interpretação do texto, mas na situação em questão havia uma busca pelo projetar de toda uma sociedade.

É evidente a necessidade de transformações de paradigmas no que se refere especificamente ao Direito Ambiental, paradigmas que possibilitem novas concepções, e recepcionem os problemas ambientais reais.

Assim, com a Hermenêutica Filosófica de Gadamer, que rompeu com os alicerces da hermenêutica clássica, se propõe a uma virada no campo interpretativo e a construção de um novo saber ambiental.

Na Hermenêutica Filosófica de Gadamer, destaca-se a tarefa da linguagem é como meio, processo, fundamento, onde é alcança-se o sentido pelo diálogo. A linguagem é uma expansão, abertura de horizontes.

O que se observou foi a elevação de fatores ditos "técnicos", fechados, e uma desconsideração dos chamados sociais. Com toda convicção, pode-se afirmar que mesmo a Constituição Federal de 1988 sendo um dos sistemas mais abrangentes e atuais do mundo no que se refere ao meio ambiente, jamais firmará fatores de Justiça ambiental sem a transformação de um saber ambiental.

O Direito ambiental é um espaço extraordinário para o desenvolvimento da Hermenêutica Filosófica de Gadamer, uma vez que nela se pressupõe a questão do ser no tempo, na história e um reconhecimento das disparidades. Assim, a Justiça ambiental ganha sentido nas mãos do intérprete.

THE CONSTRUCTION OF A NEW ENVIRONMENTAL PARADIGM: HANS-GEORG GADAMER'S PHILOSOPHICAL HERMENEUTICS AND THE (IN) CONSTITUTIONALITY OF LAW 12.651 / 2012 


\begin{abstract}
This paper analyzes the (in) constitutionality of the Forest Code - Law 12.651/2012 and proposes a new perspective based on the Gadamerian hermeneutics. The method used is the hermeneutic. It is concluded that the hermeneutics of Gadamer can bring a new understanding to the issues of environmental law, where the interpreter can glimpse the environmental justice and the change of prevailing paradigms.
\end{abstract}

Keywords: Environment; Philosophical Hermeneutics; Hans-Georg Gadamer; Constitutional right; Forest Code.

\title{
REFERÊNCIAS
}

ANTUNES, Paulo de Bessa. Comentários ao Novo Código Florestal: Atualizado de Acordo com a Lei n⿳10.727/12 - Código Florestal, $2^{\mathrm{a}}$ edição. Atlas, 05/2014. p. 02.

ANTUNES, Paulo Bessa. Direito Ambiental, 19ª edição. Atlas, 05/2017.

BENJAMIN, Antônio Herman. HERMENÊUTICA DO NOVO CÓDIGO FLORESTAL. Superior Tribunal de Justiça - Doutrina - Edição Comemorativa - 25 Anos, Brasília - Df, v. 19, p.15-24, 2014. Disponível em: $<$ http://www.stj.jus.br/publicacaoinstitucional/index.php/Dout25anos/article/view/1109/1043>. Acesso em: 17 jun. 2018.

BLEICHER, Josef. Hermenêutica contemporânea. Lisboa, Portugal: Edições 70, 2002. 383 p. (O saber da filosofia; 30).

BRASIL. Constituição (1967). Emenda Constitucional no 1, de 1969. Edita o novo texto da Constituição Federal de 24 de janeiro de 1967. Disponível em:http://www2.camara.leg.br/legin/fed/emecon/19601969/emendaconstitucional-1-17-outubro-1969-364989-publicacaooriginal-1-pl.html. Acesso em 16 de maio de 2018.

BRASIL. LEI $\mathrm{N}^{\mathrm{o}}$ 12.651, DE 25 DE MAIO DE 2012. Código Florestal. Disponível em: http://www.planalto.gov.br/ccivil_03/_ato2011-2014/2012/lei/112651.htm. Acesso em 16 de maio de 2018.

BRASIL. STF. AÇÃO DIRETA DE INCONSTITUCIONALIDADE: ADI 4901. Relator: Ministro Luiz Fux. DJ: 28/02/2018. STF, 2018. Disponível em: http://redir.stf.jus.br/estfvisualizadorpub/jsp/consultarprocessoeletronico/ConsultarProcessoEletronico.js f? seqobjetoincidente=4355097. Acesso em: 18 de junho de 2018 .

BRASIL. STF. AÇÃO DIRETA DE INCONSTITUCIONALIDADE: ADI 4902. Relator: Ministro 
Luiz Fux. $\quad$ DJ: 28/02/2018. STF, 2018. Disponível em: http://redir.stf.jus.br/estfvisualizadorpub/jsp/consultarprocessoeletronico/ConsultarProcessoEletronico.js f?seqobjetoincidente=4355128. Acesso em: 18 de junho de 2018 .

BRASIL. STF. AÇÃO DIRETA DE INCONSTITUCIONALIDADE: ADI 4903. Relator: Ministro Luiz Fux. DJ: 28/02/2018. STF, 2018. Disponível em: http://redir.stf.jus.br/estfvisualizadorpub/jsp/consultarprocessoeletronico/ConsultarProcessoEletronico.js f?seqobjetoincidente=4355144. Acesso em: 18 de junho de 2018 .

BRASIL. STF. AÇÃO DIRETA DE INCONSTITUCIONALIDADE: ADI 4937. Relator: Ministro Luiz Fux. DJ: 28/02/2018. STF, 2018. Disponível em: http://redir.stf.jus.br/estfvisualizadorpub/jsp/consultarprocessoeletronico/ConsultarProcessoEletronico.js f?seqobjetoincidente=4388129. Acesso em: 18 de junho de 2018 .

CARVALHO, Carlos Gomes de. Introdução ao direito ambiental. 3.ed. rev. e ampl. São Paulo: Letras \& Letras, 2001. 274.

COELHO, Inocêncio Mártires. Série IDP - Linha doutrina - Da hermenêutica filosófica à hermenêutica jurídica: fragmentos, $2^{\mathrm{a}}$ edição. Saraiva, 12/2014.

CONJUR. Leia o voto do ministro Celso de Mello nas ações sobre o Código Florestal. $<$ https://www.conjur.com.br/2018-fev-28/leia-voto-celso-mello-acoes-codigo-florestal $>$ Acesso em: 04 fev. 2019.

GADAMER, Hans-Georg. Verdade e método. 11. ed. Petrópolis, RJ: Vozes, 2011. 2 v. (Pensamento humano).

GADAMER, Hans-Georg. Verdade e método. 6.ed. Petrópolis, RJ: Vozes, 2004-2011. 2 v. (Coleção pensamento humano).

GRANZIERA, Maria Luiza Machado. Direito Ambiental: Revista e Atualizada, $4^{a}$ edição. Atlas, 06/2015.

GRONDIN, Jean. Introdução à hermenêutica filosófica. São Leopoldo, RS: UNISINOS, 1999.

JUNIOR, Vladimir Polízio. Novo Código Florestal - comentado, anotado e comparado. 3. ed. - São Paulo: Rideel, 2016.

LIXA, Ivone Fernandes Morcilo. Hermenêutica \& direito: uma possibilidade crítica. Curitiba: Juruá, 2003. 
MACHADO, Paulo Affonso Leme. Direito ambiental brasileiro. 12.ed. rev., atual. e ampl. São Paulo: Malheiros, 2004. 1075 p. 147.

MORAES, Alexandre de. Direito Constitucional, 33a edição. Atlas, 02/2017. [Minha Biblioteca].

MILARÉ, Édis. Direito do ambiente. 9. ed., rev., atual. e ampl. São Paulo: Revista dos Tribunais, 2014.

NAVARRO, Gabriela Cristina Braga. Hermenêutica filosófica e direito ambiental [dissertação]: concretizando a justiça ambiental/ Gabriela Cristina Braga Navarro; orientador, José Rubens Morato Leite. - Florianópolis, SC, 2014.

NAVARRO, Gabriela Cristina Braga. Hermenêutica filosófica e direito ambiental: concretizando a justiça ambiental/ Gabriela Cristina Braga Navarro; coordenadores [da série] José Rubens Morato Leite, Antonio Herman Benjamin. - São Paulo: Inst. O Direito por um Planeta Verde, 2015. - (Direito ambiental para o século XXI ; v.4).

PALMER, Richard E. Hermenêutica. Lisboa: Edições 70, s/d..

VIEGAS, Eduardo Coral. Mais prazo para a inscrição no Cadastro Ambiental Rural. 2018. Disponível em: https://www.conjur.com.br/2018-jun-16/ambiente-juridico-prazo-inscricao-cadastroambiental-rural\#_ftn4. Acesso em: 16 de Junho de 2018.

Trabalho enviado em 04 de fevereiro de 2019

Aceito em 06 de fevereiro de 2020 